\title{
Implementation of modified artificial bee colony (ABC) optimization technique for minimum cost design of welded structures
}

\author{
Vimal Savsani* \\ Department of Mechanical Engineering, Pandit Deendayal Petroleum University, Raysan, Gandhinagar 382 007, Gujarat, India
}

Received 7 June 2013 / Accepted 23 October 2013 / Published online 10 February 2014

\begin{abstract}
Welded structures are widely used in many engineering load carrying structures such as columns, towers for wind turbine or water tanks, offshore and submarine structures, girders, stiffened doors, etc. welding is a costly fabrication process and proper sequence and welding process effect the cost of a huge structure. Keeping this in view two different problems from the literature for the cost optimization of welded structures are considered in this paper. The optimization procedure is carried out using artificial bee colony (ABC) optimization technique. Classical ABC is modified to increase the convergence rate of the original algorithm. Comparison of both the variants is experimented on many bench mark examples from the literature and also on two cost optimization problems of welded structures. The results of the considered techniques are compared with the previously published results. The considered techniques have given much better results in comparison to the previously tried approaches and also modified $\mathrm{ABC}$ has shown superiority over classical ABC.
\end{abstract}

Key words: Welded structures, Optimum design, Cost optimization, Artificial bee colony.

\section{Introduction}

Stiffeners are required to improve the load carrying capacity of structures. Stiffeners help to achieve lightweight and robust design of the structure. For this purpose they have wide use in structural engineering domain. Specially, stiffened plates are used in critical and sensitive structures such as in aircrafts, ship hulls and box girders in which safety and a perfect design is crucial. Buckling is the one of the most complex phenomenon that is inevitable for heavily axially loaded stiffened plate structures. The wide area of application of such structures is an aircraft industry where light, stiff and highly resistant structures are required. It is possible to manufacture aircraft elements as thin panels reinforced by stiffeners. The proper stiffeners arrangement in a domain of the structure decides about the effectiveness of the construction or about the effectiveness of reinforcement. Optimal properties of structures can be searched using optimization tools which are discussed in the later part of this paper.

For steel structures a general total cost function $K_{\mathrm{T}}$ can be defined in the following form [19]

$$
K_{\mathrm{T}}=K_{\mathrm{m}}+K_{\mathrm{f}}+K_{\mathrm{t}}+K_{\mathrm{e}},
$$

*e-mail: vimal.savsani@gmail.com

where $K_{\mathrm{m}}$ is the material cost of structural members, $K_{\mathrm{f}}$ is the fabrication cost, $K_{\mathrm{t}}$ is the cost of transporting the fabricated pieces to the construction field, and $K_{\mathrm{e}}$ is the erection cost. Many studies are reported in literature for the cost optimization of different structures.

Anderson and Chong [4] presented the minimum cost design of homogeneous and hybrid stiffened steel plate girders according to the AISC code [2]. Douty [13] described the minimum cost design of three different types of bolted and welded connections used in steel frames based on the AISC specifications [1] The cost function is presented in terms of the connection variables, such as the diameter of the bolts, flange plate width and thickness, shear plate length and thickness, and the leg size of the fillet weld for connecting the shear plate to the column flange and for the flange plate moment connection. Lorenz [25] discussed the minimum cost design of composite beams based on the AISC load and resistance factor design (LRFD) code [3]. Farkas [15] presents closed-form solutions for optimum cost values of the cross-sectional variables for simply supported welded box girders subjected to a uniformly distributed load and constraints on bending stress, local flange and web buckling, shear fatigue for longitudinal fillet welds, and deflection. Farkas and Jarmai [16] presented the minimum cost design of laterally loaded welded cellular steel plates using 
three different approaches: the backtracking method, the hillclimbing method, and feasible sequential quadratic programming. Bhatti [7] presented the minimum cost design of simply supported composite I-shaped steel beams with concrete slabs subjected to a uniformly distributed load, and strength, deflection, and vibration constraints using the Lagrange multiplier approach. Farkas [18] derived a differential equation for the radial shell deformation using the bending theory of cylindrical shells. The solution of this equation gives an approximate formula for the maximum radial deformation. Comparing this formula with the limiting deformation given by ECCS allows calculating the required shell thickness. Another thickness can be obtained using ECCS buckling formulae. Using an interpolation, a thickness can be calculated, which fulfills the constraints. Jarmai et al. [21] demonstrated the optimal design of a cylindrical orthogonally stiffened shell member of an offshore fixed platform truss, loaded by axial compression and external pressure. Ring stiffeners of welded box section and stringers of halved rolled I-section were used. The design variables considered in the optimization were the shell thickness as well as the dimensions and numbers of stiffeners. The design constraints relate to the shell, panel ring and panel stringer buckling, as well as manufacturing limitations. The cost function includes the cost of material, forming of plate elements into cylindrical shape, welding and painting. In the optimization a number of relatively new mathematical optimization methods such as leap-frog - LFOPC, Dynamic-Q, ETOPC, and Particle swarm optimization - PSO were used. Jarmai [20] presented the single and multiobjective optimization of a welded stringer-stiffened cylindrical steel shell. A column fixed at the bottom and free on the top was constructed of stringer-stiffened cylindrical shell and loaded by axial compression as well as by horizontal force acting on the top. Halved rolled I-section stringers were welded outside of the shell by longitudinal fillet welds. Design Variables taken were the shell thickness as well as dimension and number of stringers. Three different objective functions were considered viz. material cost, forming cost to form the shell elements into the cylindrical shape, assembly and welding, and painting cost. The original PSO algorithm was modified to handle multiobjective optimization techniques and to find discrete values of design variables. Luis et al. [26] presented the optimization of a uniaxially compressed stiffened plate subjected to static and fatigue loading. The design variables were the thickness of the base plate, the number and dimension of stiffeners of the orthogonally stiffened plate. Cost optimization was carried out considering material, assembly, welding and painting costs. Farkas and Jarmai [14] presented the cost minimization of a cantilever stub column of square box cross section with orthogonally stiffened side plates. Design variables include the thickness and width of the side plates as well as the dimensions and numbers of stiffeners. PSO was implemented for the cost optimization. Marcin et al. [27] presented the optimal configuration of stiffening ribs in the steel welded I-beams and columns. The configuration with diagonal ribs is proved better than traditional ones. Farkas et al. [17] used refined version of the original Snyman-Fatti (SF) global continuous optimization algorithm to the optimal design of welded square stiffened plates. Square plates of square symmetry subjected to uniformly distributed normal static loads, supported at four corners, and stiffened by a square symmetrical orthogonal grid of ribs was investigated. Halved rolled I-section stiffeners are used welded to the base plate by double fillet welds. The cost function includes material, welding as well as painting costs, and is formulated according to the fabrication sequence. Design variables include base plate thickness as well as the dimensions of the edge and internal stiffeners. Constraints on stress in the base plate and in stiffeners, as well as on deflection of edge stiffeners and of internal stiffeners were considered. PSO algorithm was applied to confirm the results given by the SF algorithm.

It has been observed from the review of research work on design optimization of welded structures that the recently used advanced optimization technique is PSO. PSO requires many controlling parameters such as inertia weight, maximum velocity, and learning factors which influence the performance of the algorithm. Therefore the efforts are continuing to use more different optimization algorithms, which are more powerful, robust and able to provide accurate solution. This paper is intended to apply one such optimization algorithms known as artificial bee colony (ABC) [22] optimization technique. In the present work, an effort is made to verify if any improvement in the solution is possible by employing $\mathrm{ABC}$ optimization technique to two different cost optimization problems for welded structures reported in the literature. Moreover ABC optimization technique is the most recently developed technique. It is not so far tried for the complex optimization problems for structural design. The next section gives a brief description of $\mathrm{ABC}$ optimization techniques.

\section{Artificial bee colony (ABC) techniques}

Artificial bee colony $(\mathrm{ABC})$ Algorithm is an optimization algorithm based on the intelligent foraging behaviour of honey bee swarm. The colony of artificial bees consists of three groups of bees: employed bees, onlookers and scouts [5, 22].

The colony of the artificial bees is divided into two groups, first half of the colony consists of the employed artificial bees and the second half includes the onlooker bees. Scout bees are the employed bee whose food source has been abandoned. In $\mathrm{ABC}$ algorithm, the position of a food source represents a possible solution to the optimization problem (value of design variables) and the nectar amount of a food source corresponds to the quality of the associated solution (value of objective function). At the first step, the $\mathrm{ABC}$ generates a randomly distributed initial population $P_{\text {initial }}$ of $N$ solutions, where $N$ denotes the size of population. Each solution $x_{i}$ is an $S$-dimensional vector where $S$ is the number of optimization parameters (design variables). After initialization, the population of the solutions is subjected to repeated cycles, $C=1,2, \ldots, G$, of the search processes of the employed bees, the onlooker bees and scout bees. An employed bee which is equal to N/2 produces a modification on the solution in her memory depending on the local information. If the objective function value (fitness) of the new solution is higher than that of the previous one, the bee memorizes the new position and forgets the old one. Otherwise she keeps the position of the previous one in her memory. After all employed bees complete the search process; they share the nectar information of the food sources and their position 
information with the onlooker bees on the dance area. An onlooker bee evaluates the fitness information taken from all employed bees and chooses a food source with a probability related to its fitness value. An onlooker bee also produces a new solution and it memorizes the new position if its fitness value is better than the previous position. An artificial onlooker bee chooses a food source depending on the probability value associated with that food source, $p_{i}$, calculated by the following expression

$$
p_{i}=\frac{F_{i}}{\sum_{n=1}^{N_{b}} F_{n}},
$$

where $F_{i}$ is the fitness value of the solution $i$ which is proportional to the nectar amount of the food source in the position $i$ and $N_{b}$ is the number of food sources which is equal to the number of employed bees. In order to produce a candidate food position from the old one in memory, the $\mathrm{ABC}$ uses the following expression (3):

$$
v_{i j}=x_{i j}+R_{i j}\left(x_{i j}-x_{k j}\right),
$$

where $k \in\{1,2, \ldots, N\}$ and $j \in\{1,2, \ldots, D\}$ are randomly chosen indexes. Although $k$ is determined randomly, it has to be different from $i . R_{i j}$ is a random number between $(-1,1)$. It controls the production of neighbour food sources around $x_{i j}$ and represents the comparison of two solutions. As can be seen from (3), as the difference between the parameters of the $x_{i j}$ and $x_{k j}$ decreases, the perturbation on the position $x_{i j}$ gets decrease, too. Thus, as the search approaches to the optimum solution in the search space, the step length is adaptively reduced.

If the position of the food source cannot be improved for some predetermined number of cycles than that food source is abandoned. The abandoned food source is replaced with a new food source by the scouts. In ABC, this is simulated by producing a position randomly and replacing it with the abandoned one. The value of predetermined number of cycles is an important control parameter of the $\mathrm{ABC}$ algorithm, which is called "limit" for abandonment. The value of limit is generally taken as Number of employed bees* $S[23,24]$.

Assume that the abandoned source is $x_{i}$ and $j \in\{1,2, \ldots$, $D\}$, then the scout discovers a new food source to be replaced with $x_{i}$. This operation can be defined as in (4)

$$
x_{i}^{j}=x_{\min }^{j}+\operatorname{rand}(0,1)\left(x_{\max }^{j}-x_{\min }^{j}\right) \text {. }
$$

It is clear from the above explanation that there are three control parameters used in the ABC: The number of food sources which is equal to the number of employed or onlooker bees $(N)$, the value of limit, the maximum cycle number $(G)$.

As suggested by Karaboga [22] $R_{i j}$ is uniformly distributed random number between -1 and 1 . In this paper ABC is modified by using normally distributed random number with mean 0 and variance 1 instead of uniformly distributed random number between -1 and 1 . The distributions of both the random numbers generated using MATLAB with $1 \mathrm{e} 7$ random points are shown in Figures 1 and 2 respectively.

Another modification is made in equation (3) by replacing $\left(x_{i j}-x_{i k}\right)$ by $\left(x_{\text {best } j}-x_{i j}\right)$. Here $x_{\text {best } j}$ is the best solution from the population. The reason is that in the earlier formula the

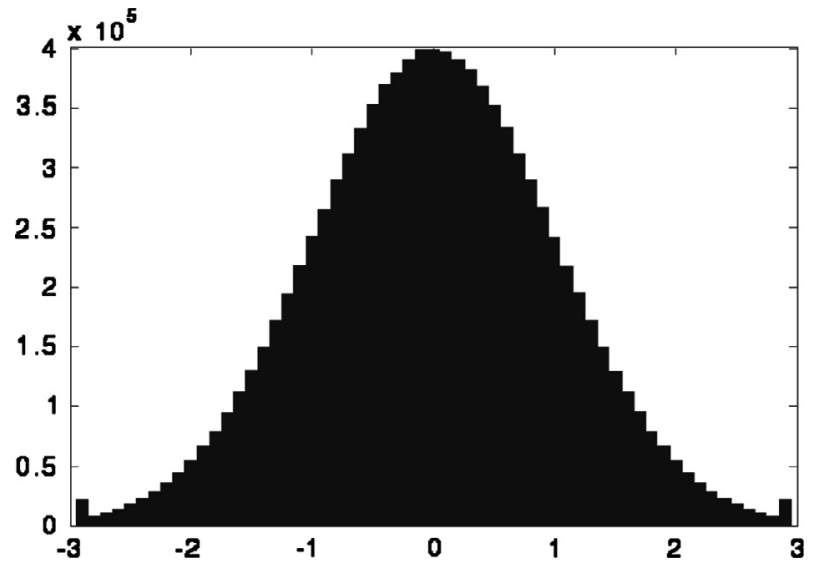

Figure 1. Normal distribution of $1 \mathrm{e} 7$ random numbers with mean 0 and variance 1 .

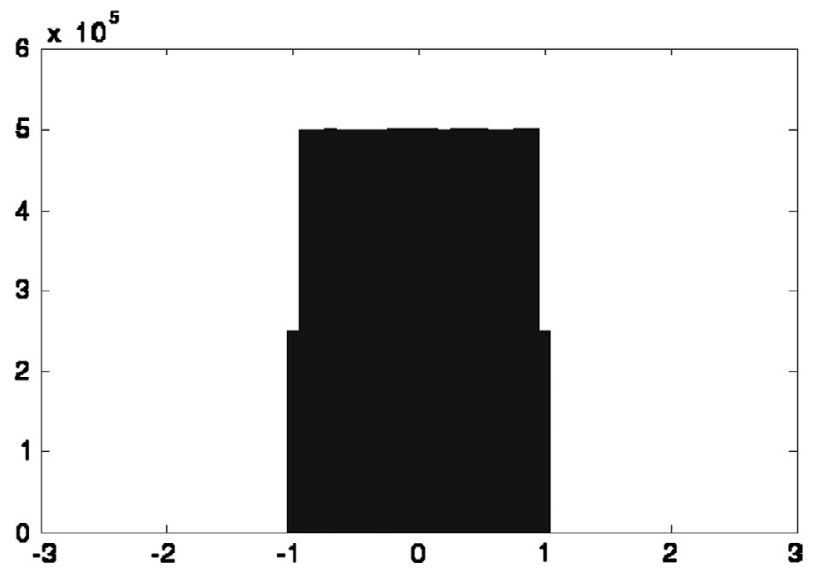

Figure 2. Uniformly distributed random number between -1 and 1 for $1 \mathrm{e} 7$ random points.

solution tries to move towards any random solution $\left(x_{i k}\right)$. There is no guarantee for the $x_{i k}$ to be better than $x_{i j}$. So solution can move towards worst solution also, which may require more computational time to reach the optimum solution. By replacing $x_{i k}$ with $x_{\text {best }}$, the solution will always move towards the best solution in each iteration, which will lead to global optimum solution in less computational effort. Moreover effort is made to increase the convergence rate of the original $\mathrm{ABC}$ algorithm. Many experiments were conducted to change equation (3) so that algorithm converges to optimum solution in less number of generations. In this paper original $\mathrm{ABC}$ will be referred as $\mathrm{ABC} \_1$ and modified $\mathrm{ABC}$ as $\mathrm{ABC} \_2$. Experiments shows that by using $\mathrm{ABC} 2$ solutions improves by approximately $87 \%$ and by using $\mathrm{ABC}$ _ 1 solutions improves by $39 \%$ in successive first five generations which indicates the fast convergence rate of modified $\mathrm{ABC}$. Convergence rate for the benchmark Sphere function $\left(f(X)=\sum_{i=1}^{n} x_{i}^{2}, x \in[-100100], i=20\right)$ for five different runs for both the variants of $\mathrm{ABC}$ is shown in Figures 3 and 4. From Figures 3 and 4 also it can be noted that modified $\mathrm{ABC}$ have better convergence than classical $\mathrm{ABC}$.

The algorithm discussed above takes real number in the aspect of representation solution and updates themselves with 


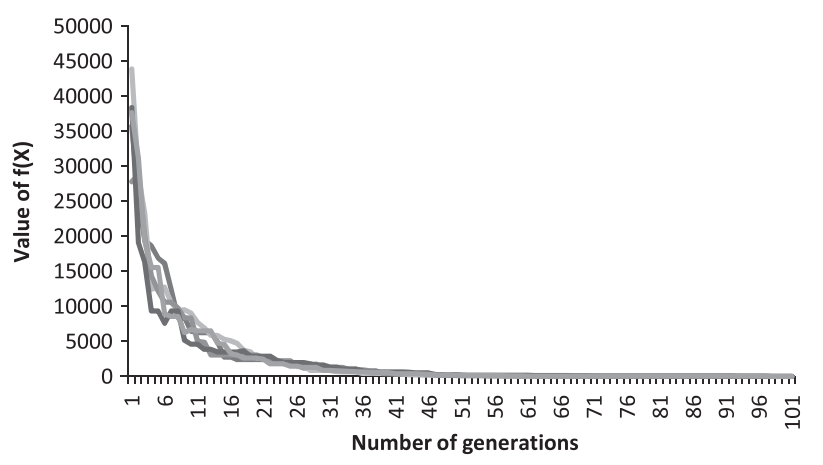

Figure 3. Variation of solution for the sphere function for classical $\mathrm{ABC}$ for five different runs.

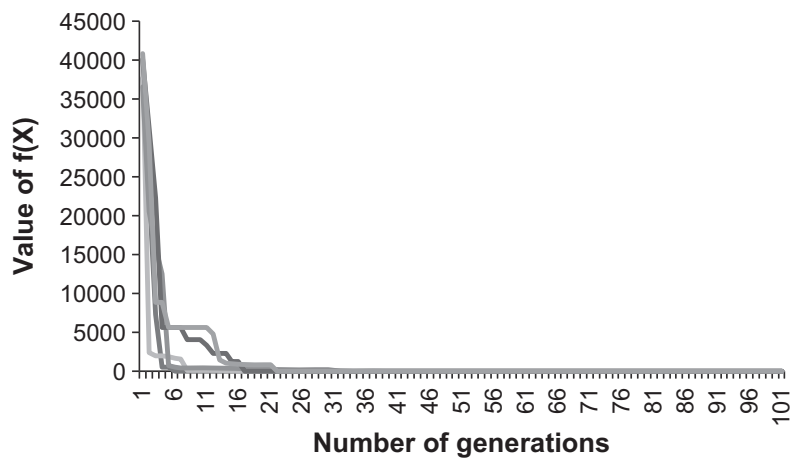

Figure 4. Variation of solution for the sphere function for modified $\mathrm{ABC}$ for five different runs.

certain rules based on the behavior of algorithm. In this algorithm, process looks only for the best solution and tends to converge to the best solution. In the implementation process, solutions are randomly generated at the beginning and usually violate the system constraints resulting in infeasible solutions. Therefore, the handling of system constraints, particularly nonlinear equation constraints, and the measurement and evaluation of infeasible solutions is very important. To cope with constrained problems with evolutionary computation, various approaches such as rejection of infeasible individuals, repair of infeasible individuals, replacement of individuals by their repaired versions, and penalty function methods can be adopted. Among them, the penalty function method is particularly promising as evidenced by recent developments [12] and the same is adapted in the present work. Penalty function changes the constrained optimization problem into unconstrained optimization problem. For example consider an optimization problem as

$$
\text { Minimize : } f(X) \text {, Subjected to }: g_{i}(X) \geq 0 \text {. }
$$

This problem is converted in unconstrained form as

$$
\begin{gathered}
\text { Minimize : } f(X), \text { if } g_{i}(X) \geq 0, \text { else, } \\
\text { Minimize : } f(X)+R \sum_{i=1}^{n} g_{i}(X),
\end{gathered}
$$

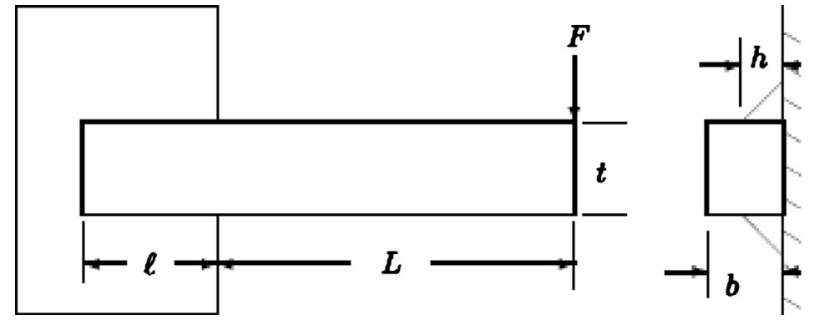

Figure 5. Welded beam design (Example 1).

where $R$ is very large number and $n$ is number of constraints.

The next section presents examples to demonstrate and validate the considered optimization techniques for the cost optimization of welded structures.

\section{Examples}

To check the performance of $\mathrm{ABC}$ some classical benchmark problems from Karaboga and Basturk [24] were experimented. In experiments, Schaffer function has two parameters $(-100 \leq X \leq 100)$, while Sphere $\quad(-100 \leq X \leq 100)$, Griewank $(-600 \leq X \leq 600)$, Rastrigin $(-5.12 \leq X \leq 5.12)$ and Rosenbrock $(-50 \leq X \leq 50)$ functions have 20 parameters each. Moreover some engineering benchmark problems were also taken for the investigation. They include pressure vessel problem [32] consisting of four design variable and four constraints, Spring weight minimization problem [6]) consisting of three design variable and four constraints, and speed reducer problem [28] consisting of 7 design variables and 11 constraints. As this paper focuses on the optimization of welded structures two special problems of welded structure optimization is taken from the literature and is given in detail as follows. More detailed information can be obtained from the mentioned reference. Experiments were conducted for different population size and number of generations. In this paper N50G200 indicates population size of 50 with number of generation of 200. Results were obtained for 50 different runs.

\subsection{Example - 1 welded beam}

The objective is to design a welded beam for minimum cost. There are four design variables as shown in Figure 5: $h\left(x_{1}\right), l\left(x_{2}\right), t\left(x_{3}\right)$ and $b\left(x_{4}\right)$. Design is subjected to the constraints on shear stress $(\tau)$, bending stress in the beam $(\sigma)$, buckling load on the bar $\left(P_{c}\right)$, end deflection of the beam $(\delta)$, and side constraints.

The problem can be stated as follows:

$$
\begin{aligned}
\text { Minimize } & : f(x) \\
& =1.10471 x_{1}^{2} x_{2}+0.04811 x_{3} x_{4}\left(14.0+x_{2}\right) .
\end{aligned}
$$

Subject to:

$$
g_{1}(x)=\tau(x)-\tau_{\max } \leq 0,
$$



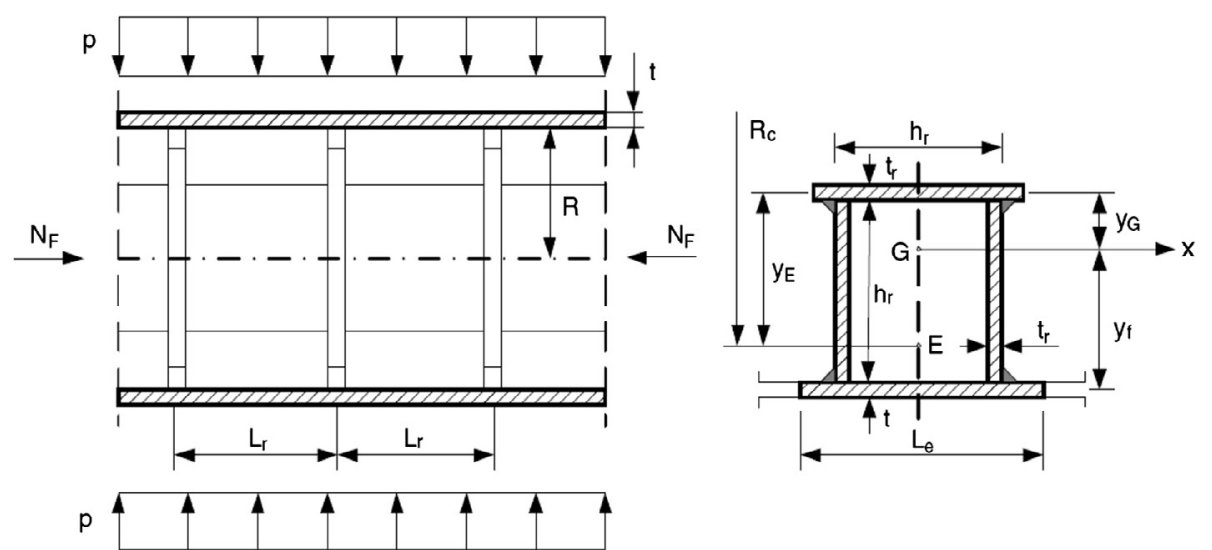

Figure 6. Orthogonally stiffened cylindrical shell with stringer and ring stiffener acted by compression and external pressure [21].

$$
\begin{gathered}
g_{2}(x)=\sigma(x)-\sigma_{\max } \leq 0, \\
g_{3}(x)=x_{1}-x_{4} \leq 0, \\
g_{4}(x)=0.10471 x_{1}^{2}+0.04811 x_{3} x_{4}\left(14.0+x_{2}\right)-5.0 \\
\leq 0,
\end{gathered}
$$

where

$$
\begin{gathered}
\tau(x)=\sqrt{\left(\tau^{\prime}\right)^{2}+2 \tau^{\prime} \tau^{\prime \prime} \frac{x_{2}}{2 R}+\left(\tau^{\prime \prime}\right)^{2}} \\
\tau^{\prime}=\frac{P}{\sqrt{2} x_{1} x_{2}} \\
\tau^{\prime \prime}=\frac{M R}{J} \\
M=P\left(L+\frac{x_{2}}{2}\right), \\
R=\sqrt{\frac{x_{2}^{2}}{4}+\left(\frac{x_{1}+x_{3}}{2}\right)^{2}}, \\
J=2\left[\sqrt{2} x_{1} x_{2}\left\{\frac{x_{2}^{2}}{12}+\left(\frac{x_{1}+x_{3}}{2}\right)^{2}\right\}\right]
\end{gathered}
$$

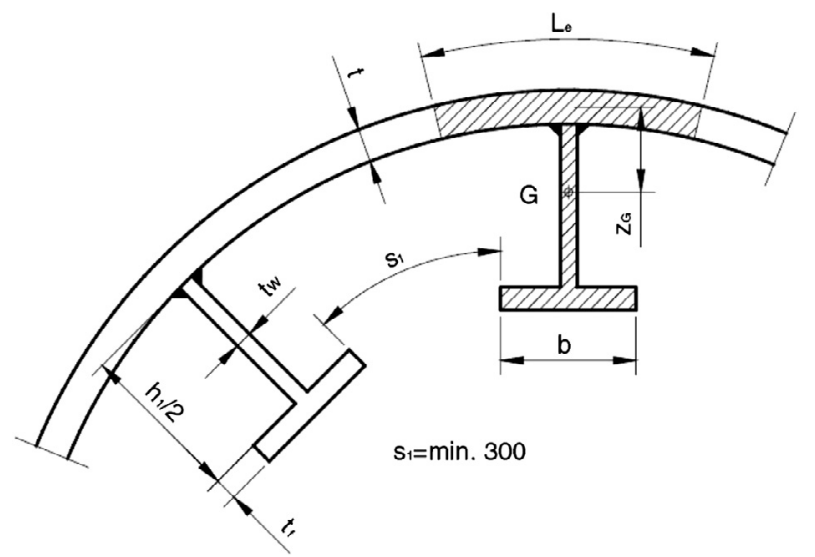

Figure 7. Halved rolled I - section as a stringer [21].

$$
\sigma(x)=\frac{6 P L}{x_{4} x_{3}^{2}}
$$

$$
\delta(x)=\frac{4 P L^{3}}{E x_{3}^{3} x_{4}}
$$

$$
P_{c}(x)=\frac{4.013 E \sqrt{\frac{x_{3}^{2} x_{4}^{6}}{36}}}{L^{2}}\left(1-\frac{x_{3}}{2 L} \sqrt{\frac{E}{4 G}}\right)
$$$$
P=6000 \mathrm{lb}, L=14 \mathrm{in}, E=30 \mathrm{e} 6 \mathrm{psi}, \mathrm{G}=12 \mathrm{e} 6 \mathrm{psi}
$$$$
\tau_{\max }=13600 \mathrm{psi}, \sigma_{\max }=30000 \mathrm{psi}, \delta_{\max }=0.25 \mathrm{in}
$$$$
0.1 \leq x_{1} \leq 2.0,0.1 \leq x_{2} \leq 10.0,0.1 \leq x_{3} \leq 10.0,0.1
$$

$$
\leq x_{4} \leq 2.0
$$

\subsection{Example-2 orthogonally stiffened cylindrical shell}

Objective is to optimize cost of a cylindrical shell member that is orthogonally stiffened by using ring stiffeners of box cross section and stringers of halved I-section Figures 6 and 7. 
The cost function includes material cost, manufacturing cost and painting cost.

Cost function is given by [21]

$$
K=K_{M}+\sum_{i} K_{F i}+K_{P},
$$

where $K_{M}$ is the material cost, $K_{F}$ is the fabrication cost and $K_{P}$ is the painting cost.

The manufacturing cost is derived from the manufacturing sequence which is explained as follows:

$\left(K_{F 0}\right)$ Cylindrical shapes are formed from plate elements of $3 \mathrm{~m}$ length $\left(L_{s}\right)$.

$$
K_{F 0}=5 k_{F} \theta e^{\mu}
$$

$\left(K_{F 1}\right) 3 \mathrm{~m}$ shell segments are welded from two curved plate elements with two butt welds using gas metal arc welding.

$$
\begin{aligned}
K_{F 1}= & 5 k_{F}\left(\theta \sqrt{2 \rho V_{1}}\right. \\
& +(1.3)\left(0.1520 \times 10^{-3} t^{1.9358}\right)\left(2 L_{s}\right) .
\end{aligned}
$$

$\left(K_{F 2}\right) 15 \mathrm{~m}$ un-stiffened shell is welded from five shell segments with four circumferential butt welds using gas metal arc welding.

$$
\begin{aligned}
K_{F 2}= & k_{F}\left(\theta \sqrt{25 \rho V_{1}}\right. \\
& +(1.3)\left(0.1520 \times 10^{-3} t^{1.9358}\right)(8 R \pi) .
\end{aligned}
$$

$\left(K_{F 3}\right) \mathrm{nr}$ ring stiffeners are welded from three plate elements with two fillet welds each using shielded metal arc welding.

$$
K_{F 3}=n_{r} k_{F}\left[3 \sqrt{3 \rho V_{R}}+1.3 \times 0.3394 X 10^{-3} a_{w r}^{2} 4 \pi\left(R-h_{r}\right)\right] \text {. }
$$

$\left(K_{F 4}\right) \mathrm{nr}$ ring stiffeners are welded into the whole shell with $2 \mathrm{nr}$ circulferential fillet welds using shielded metal arc welding.

$$
\begin{gathered}
K_{F 4}=k_{F}\left[3 \sqrt{\left(n_{r}+1\right) \rho\left(5 V_{1}+n_{r} V_{R}\right)}\right. \\
\left.+1.3 X 0.3394 X 10^{-3} a_{w r}^{2} n_{r} 4 \pi R\right] .
\end{gathered}
$$

$\left(K_{F 5}\right)$ ns stringers are welded into the shell with 2 ns fillet welds using shielded metal arc welding.

$$
\begin{aligned}
K_{F 5}=k_{F} & {\left[3 \sqrt{\left(n_{r}+n_{s}+1\right) \rho\left(5 V_{1}+n_{r} V_{R}+n_{s} A_{s} L\right)}\right.} \\
& \left.+1.3 X 0.3394 X 10^{-3} a_{w s}^{2} n_{s} 2 L\right] .
\end{aligned}
$$

The material cost is given by

$$
K_{M}=k_{M 1} 5 \rho V_{1}+k_{M 1} \rho n_{r} V_{R}+K_{M 2} \rho n_{s} A_{s} L,
$$

where $V_{1}$ is the volume of the shell segment and $V_{R}$ is the volume of ring stiffener.

The painting cost is given by

$$
K_{P}=k_{P}\left[2 R \pi L+2 R \pi\left(L-n_{r} h_{r}\right)+2 n_{r} \pi h_{r}\left(R-h_{r}\right)\right.
$$

$$
\left.+4 \pi R h_{r}\left(R-\frac{h_{r}}{2}\right)+n_{s} L\left(h_{1}+2 b\right)\right]
$$

Shell buckling constraint $g_{1}(X)$ associated with the design is given by [11]

$$
\sigma e=\sqrt{\sigma_{a}^{2}-\sigma_{a} \sigma_{p}+\sigma_{p}^{2}} \leq f_{y 1} / \sqrt{1+\lambda_{s}^{4}},
$$

where $\sigma_{e}$ is the equivalent stress according to Det Norske Veritas rules. And $\sigma_{a}=N_{F} / 2 R \pi t_{e} ; t_{e}=t+A_{s s} ; s=2 R \pi / n_{s}$; $\sigma_{p}=p_{F} R / t(1+\alpha) ; \quad \alpha=A_{R} / L_{e 0} t ; \quad L_{e 0}=\min \left(L_{r}, L_{e r}\right)=$ $1.56 \sqrt{R t} ; \quad L_{r}=\frac{L}{n_{r}}-1 ; \quad \lambda_{s}^{2}=\frac{f_{y 1}}{\sigma_{e}}\left(\frac{\sigma_{a}}{\sigma_{\text {Eas }}}+\frac{\sigma_{p}}{\sigma_{\text {Eps }}}\right) ; \quad \sigma_{\text {Eas }}=$ $C_{a s} \frac{\pi^{2} E}{12\left(1-\gamma^{2}\right)}\left(\frac{t}{s}\right)^{2} ; \quad C_{\text {as }}=\Psi_{a s} \sqrt{1+\left(\frac{\rho_{a s} \xi_{a s}}{\Psi_{a s}}\right)^{2}} ; \quad \Psi_{a s}=4 ;$ $Z_{a s}=\frac{s^{2}}{R t} \sqrt{1-v^{2}} ; \quad \xi_{a s}=0.702 Z_{a s} ; \quad \rho_{a s}=0.5\left(1+\frac{R}{150 t}\right)^{-0.5}$; $\sigma_{E p s}=C_{p s} \frac{\pi^{2} E}{10.92}\left(\frac{t}{s}\right)^{2} ; \quad C_{p s}=\Psi_{p s} \sqrt{1+\left(\frac{\rho_{p s} \xi_{p s}}{\Psi_{p s}}\right)^{2}} ; \quad \rho_{p s}=0 . ;$ $\xi_{p s}=1.04 \frac{s}{L_{r}} \sqrt{Z_{p s}} ; Z_{p s}=Z_{a s} ; \Psi_{p s}=\left[1+\left(\frac{s}{L_{r}}\right)^{2}\right]^{2}$.

Stringer buckling constraint $g_{2}(X)$ is given by

$$
\sigma_{e} \leq \frac{f_{y 1}}{\sqrt{1+\lambda_{p}^{4}}},
$$

where, $\quad \lambda_{p}^{2}=\frac{f_{y 1}}{\sigma_{e}}\left(\frac{\sigma_{a}}{\sigma_{E a p}}+\frac{\sigma_{p}}{\sigma_{E p p}}\right) ; \quad \sigma_{E a p}=C_{a p} \frac{\pi^{2} E}{10.92}\left(\frac{t}{L_{r}}\right)^{2} ; \quad C_{a p}=$

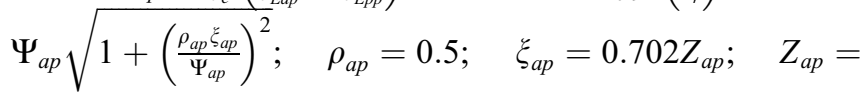
$\frac{L_{r}^{2}}{R t} 0.9539 ; \quad \Psi_{a p}=\frac{1+\gamma_{s}}{1+\frac{A_{s}}{s e t}} ; \quad \gamma_{s}=10.92 \frac{I_{s e f}}{s t^{t}} ; \quad s_{E}=1.9 t \sqrt{\frac{E}{f_{y}}} ;$ $Z_{G}=\frac{\frac{h_{1}}{2} t_{w}\left(\frac{h_{1}}{4}+\frac{t}{2}\right)+b t_{f}\left(\frac{h_{1}+t+t_{f}}{2}\right)}{s_{e} t+b t_{f}+\frac{h_{1} t_{w}}{2}} ; \quad$ if $\quad s_{E} \leq s, s_{e}=s_{E}, \quad$ else $s_{E} \geq s, s_{e}=s ; \quad I_{s e f}=s_{e} t z_{G}^{2}+\left(\frac{h_{1}}{2}\right)^{3} \frac{t_{w}}{12}+\frac{h_{1} t_{w}}{2}\left(\frac{h_{1}}{4}+\frac{t}{2}-z_{G}\right)^{2}+$ $b t_{f}\left(\frac{h_{1}+t+t_{f}}{2}-z_{G}\right)^{2} ; \quad A_{s}=b t_{f}+\frac{h_{1} t_{w}}{2}, \quad \sigma_{E p p}=C_{p p} \frac{\pi^{2} E}{10.92}\left(\frac{t}{L_{r}}\right)^{2}$, $C_{p p}=\Psi_{p p} \sqrt{1+\left(\frac{\rho_{p p} \xi_{p p}}{\Psi_{p p}}\right)^{2}} ; \quad \xi_{p p}=1.04 \sqrt{Z_{p p}}, \quad Z_{p p}=Z_{a p}$, $\rho_{p p}=0.6, \Psi_{p p}=2\left(1+\sqrt{1+\gamma_{s}}\right)$.

Panel ring buckling constraints $g_{3}(X)$ and $g_{4}(X)$ are given by

$$
A_{\text {Rreq }} \leq A_{R} \text { and } I_{\text {Rreq }} \leq I_{R}
$$

where, $\quad \frac{1}{\delta_{r}}=42 \varepsilon, \varepsilon=\sqrt{\frac{235}{f_{y}}} ; \quad f_{y}=355 ; \quad \delta_{r}=1 / 34 ;$ $A_{r}=3 h_{r} t_{r}=3 \delta_{r} h_{r}^{2} ; \quad A_{\text {Rreq }}=\left(\frac{2}{Z^{2}}+0.06\right) L_{r} t ; \quad Z=\frac{L_{r}^{2}}{R t} 0.9539 ;$ $L_{e}=\min \left(L_{r}, 2 \times 1.56 \sqrt{R t}\right) ; \quad y_{E}=\frac{L_{e} t\left(h_{r}+\frac{t}{2}\right)+\delta_{r} h_{r}^{3}}{3 \delta_{r} h_{r}^{2}+L_{e} t} ; I_{R}=\frac{\delta_{r} h_{r}^{4}}{6}+$ $2 \delta_{r} h_{r}^{2}\left(\frac{h_{r}}{2}-y_{E}\right)^{2}+\delta_{r} h_{r}^{2} y_{E}^{2}+L_{e} t\left(h_{r}+\frac{t}{2}-y_{E}\right)^{2} ; I_{\text {Rreq }}=I_{a}+I_{p} ;$ $I_{a}=\frac{\sigma_{a} t\left(1+\frac{A s}{s t}\right) R_{0}^{4}}{500 E L_{R}} ; \quad R_{0}=R-\left(h_{r}-y_{E}\right) ; \quad I_{p}=\frac{p_{F} R R_{0}^{2} L_{r}}{3 E}$ $\left[2+\frac{3 E y_{E} \delta_{0}}{R_{0}^{2}\left(\frac{f_{v}}{2}-\sigma_{p}\right)}\right] ; \delta_{0}=0.005 R$.

Manufacturing constraint $g_{5}(X)$ is given by

$$
\frac{2\left(R-\frac{h_{r}}{2}\right) \pi}{n_{s}}-b \geq 300, \mathrm{~mm} .
$$


Table 1. Comparison of two different variants of $\mathrm{ABC}$ for different benchmark problems.

\begin{tabular}{|c|c|c|c|c|c|c|c|}
\hline \multirow[b]{2}{*}{ Benchmark problems } & \multirow[b]{2}{*}{ Function evaluations } & \multicolumn{3}{|c|}{$\mathrm{ABC} \_1$} & \multicolumn{3}{|c|}{$\mathrm{ABC} \_2$} \\
\hline & & Best & Mean & $S D$ & Best & Mean & $S D$ \\
\hline Sphere & 10000 & 0.000088 & 0.00037112 & $1.95 \mathrm{E}-04$ & $\mathbf{0}$ & 0.0000636 & 1.13E-04 \\
\hline Rastrigin & 10000 & 12.144862 & 26.75682439 & $9.65 \mathrm{E}+00$ & 0 & 1.21746087 & $4.25 \mathrm{E}+00$ \\
\hline Rosenbrock & 200000 & 17.093176 & 51.52220345 & $9.34 \mathrm{E}+01$ & 0.201002 & 12.22409523 & $7.05 E+00$ \\
\hline Griewank & 20000 & 0.001143 & 0.010804619 & $9.20 E-03$ & 0.000373 & 0.03364881 & $5.19 \mathrm{E}-02$ \\
\hline Schaffer & 10000 & 0 & 0.0085749 & $3.03 \mathrm{E}-03$ & 0 & 0.00609025 & 4.69E- 03 \\
\hline Pressure vessel & 10000 & 6059.714335 & 6059.71437 & 1.53E-04 & 6059.714335 & 6061.566119 & $4.53 \mathrm{E}+00$ \\
\hline Spring & 5000 & 0.012676 & 0.012681389 & 2.17E-06 & 0.012667 & 0.0126805 & 4.94E-06 \\
\hline Gear box & 5000 & 2996.351945 & 2996.360606 & $6.56 \mathrm{E}-03$ & 2996.348657 & 2996.349589 & $7.86 \mathrm{E}-04$ \\
\hline
\end{tabular}

Table 2. Comparison of different variants of $\mathrm{ABC}$ algorithm for Example 1 (welded beam) with different function evaluations for the best solutions obtained in 100 runs.

\begin{tabular}{lccccc}
\hline & \multicolumn{3}{c}{ ABC_1 } & & \multicolumn{2}{c}{ ABC_2 } \\
\cline { 2 - 4 } \cline { 5 - 6 } FE & Best & Mean & $S D$ & Best & Mean \\
\hline 1000 & 2.118958 & 2.666595 & 0.314317 & 1.749212 & 2.222916 \\
2000 & 1.814226 & 2.392055 & 0.259713 & 1.725834 & 2.114724 \\
4000 & 1.790327 & 2.099398 & 0.194092 & 1.72486 & 0.455776 \\
2500 & 1.993107 & 2.453174 & 0.231802 & 1.728703 & 0.480265 \\
5000 & 1.892304 & 2.188238 & 0.162927 & 1.724973 & 1.94462 \\
10000 & 1.802669 & 1.999135 & 0.105969 & 1.724855 & 0.368859 \\
\hline
\end{tabular}

Table 3. Comparison of different variants of $\mathrm{ABC}$ algorithm for Example 2 (Orthogonally stiffened cylindrical shell) with different function evaluations for the best solutions obtained in 100 runs.

\begin{tabular}{|c|c|c|c|c|c|c|}
\hline & \multicolumn{3}{|c|}{$\mathrm{ABC} \_1$} & \multicolumn{3}{|c|}{$\mathrm{ABC} 2$} \\
\hline & Best & Mean & $S D$ & Best & Mean & $S D$ \\
\hline 1000 & 55146.36 & 56941.54 & 907.9698 & 54530.05 & 56518.38 & 963.8605 \\
\hline 2000 & 54668.13 & 55832.04 & 702.165 & 54468.28 & 55730.39 & 732.8504 \\
\hline 4000 & 54395.24 & 55025.25 & 488.9624 & 54370.12 & 55076.65 & 745.5146 \\
\hline 2500 & 54821.67 & 56497.6 & 695.8313 & 54445.53 & 55616.16 & 845.8954 \\
\hline 5000 & 54657.63 & 55523.57 & 476.3063 & 54372.41 & 54980.24 & 690.8988 \\
\hline 10000 & 54429.48 & 54738.18 & 237.6145 & 54369.73 & 54686.88 & 593.0451 \\
\hline
\end{tabular}

Table 4. Comparison of different variants of $\mathrm{ABC}$ algorithm for Example 1 (welded beam) with different function evaluations for the success rate obtained in 100 runs.

\begin{tabular}{lcc}
\hline & ABC_1 & ABC_2 \\
\hline 1000 & 0 & 0 \\
2000 & 0 & 0.19 \\
4000 & 0 & 0.2 \\
2500 & 0 & 0.08 \\
5000 & 0 & 0.27 \\
10000 & 0 & 0.61 \\
\hline
\end{tabular}

Example 1 is solved by many researchers using different optimization techniques, including Ragsdell and Phillips [30] using geometric programming, Deb [10] using Genetic Algorithm, Coello [9] using GA based coevolution model, Coello and Montes [8] using flexibility based tournament selection scheme, Ray and Liew [31] using society and civilization algorithm and Qie and Ling [29] using effective co-evolutionary particle swarm optimization.
Table 5. Comparison of different variants of $A B C$ algorithm for Example 2 (Orthogonally stiffened cylindrical shell)) with different function evaluations for the success rate obtained in 100 runs.

\begin{tabular}{lcc}
\hline & ABC_1 & ABC_2 \\
\hline 1000 & 0 & 0.07 \\
2000 & 0.06 & 0.35 \\
4000 & 0.59 & 0.78 \\
2500 & 0.01 & 0.3 \\
5000 & 0.09 & 0.73 \\
10000 & 0.76 & 0.87 \\
\hline
\end{tabular}

Jarmai et al. [21] solved Example 2 using PSO technique for the cost optimization considering the above design variables, objective functions, and the constraints. Value of cognitive learning coefficient and social learning coefficient was taken as 2 and 1.4 respectively. Population size was varied from 1 to 500 and maximum allowable function evaluations were 100000 with no improvement termination criterion as 10 iterations. The same problem was also solved using three different 
Table 6. Comparison of results obtained by different researchers using different optimization techniques for Example 1 (welded beam).

\begin{tabular}{lccccccc}
\hline & Ragsdell \& Phillips & Deb & Coello & Coello \& Montes & Ray \& Liew & Qie \& Ling & Our approach \\
& {$[30]$} & {$[10]$} & {$[9]$} & {$[8]$} & {$[31]$} & 2009 \\
\hline$x_{1}$ & 0.2455 & 0.2489 & 0.2088 & 0.205986 & 0.244438 & 0.202369 & $\mathbf{0 . 2 0 5 7 3}$ \\
$x_{2}$ & 6.196 & 6.173 & 3.4205 & 3.471328 & 6.237967 & 3.544214 & $\mathbf{3 . 4 7 0 4 8 8}$ \\
$x_{3}$ & 8.273 & 8.1789 & 8.9975 & 9.020224 & 8.288576 & 9.04821 & $\mathbf{9 . 0 3 6 6 2}$ \\
$x_{4}$ & 0.2455 & 0.2533 & 0.21 & 0.20648 & 0.244566 & 0.205723 & $\mathbf{0 . 2 0 5 7 3}$ \\
$g_{1}(x)$ & -5743.826 & -5758.603 & -0.337812 & -0.074092 & -5760.1104 & -12.83979 & $-\mathbf{0 . 0 1 3 4}$ \\
$g_{2}(x)$ & -4.715097 & -255.5769 & -353.9026 & -0.266227 & -3.245428 & -1.247467 & $-\mathbf{0 . 0 7 3}$ \\
$g_{3}(x)$ & 0 & -0.0044 & -0.0012 & -0.000495 & -0.000128 & -0.001498 & $\mathbf{0}$ \\
$g_{4}(x)$ & -3.020289 & -2.982866 & -3.411865 & -3.430043 & -3.020055 & -3.429347 & $-\mathbf{3 . 4 3 3}$ \\
$g_{5}(x)$ & -0.1205 & -0.1239 & -0.0838 & -0.080986 & -0.119438 & -0.079381 & $-\mathbf{0 . 0 8 0 7}$ \\
$g_{6}(x)$ & -0.234208 & -0.23416 & -0.235649 & -0.235514 & -0.234237 & -0.235536 & $-\mathbf{0 . 2 3 5 5}$ \\
$g_{7}(x)$ & -3604.275 & -4465.27 & -363.2323 & -58.66644 & -13.079305 & -11.68135 & $-\mathbf{0 . 0 3 2 9}$ \\
$f(x)$ & 2.385937 & 2.433116 & 1.748309 & 1.728226 & 2.38119 & 1.728024 & $\mathbf{1 . 7 2 4 8 5 5}$ \\
\hline
\end{tabular}

Table 7. Top ten optimum solution obtained for example 1 using ABC.

\begin{tabular}{lcccccc}
\hline & $x_{1}$ & $x_{2}$ & $x_{3}$ & $x_{4}$ & $\mathrm{f}(X)$ & Max. constraint violation \\
\hline 1 & 0.20573 & 3.470488 & 9.03662 & 0.20573 & 1.72486 & - \\
2 & 0.20573 & 3.470484 & 9.036627 & 0.20573 & 1.72486 & - \\
3 & 0.205725 & 3.470603 & 9.036626 & 0.20573 & 1.72486 & - \\
4 & 0.205732 & 3.470446 & 9.036702 & 0.205731 & 1.72487 & - \\
5 & 0.205723 & 3.470624 & 9.036645 & 0.205733 & 1.72489 & - \\
6 & 0.205728 & 3.470573 & 9.036595 & 0.205734 & 1.72489 & - \\
7 & 0.20572 & 3.470761 & 9.036576 & 0.205733 & 1.72489 & - \\
8 & 0.205714 & 3.470808 & 9.036791 & 0.205734 & 1.72493 & - \\
9 & 0.205712 & 3.471132 & 9.03687 & 0.20573 & 1.72496 & \\
10 & 0.205694 & 3.471154 & 9.037005 & 0.205733 & 1.72498 & \\
\hline
\end{tabular}

Table 8. Top ten optimum solutions obtained for example 2 using ABC.

\begin{tabular}{lccccccc}
\hline & $x_{1}$ & $x_{2}$ & $x_{3}$ & $x_{4}$ & $x_{5}$ & $f(X)$ & Max. constraint violation \\
\hline 1 & 13.8275 & 26.8855 & 8.3799 & 260.3097 & 223.9656 & 54444.50 & - \\
2 & 13.767484 & 27.09977 & 8.75685 & 256.76358 & 214.443837 & 54377.00 & $(1) 0.007$ \\
3 & 13.76841 & 26.8238 & 8.20406 & 262.09579 & 229.150404 & 54390.00 & $(1) 0.003$ \\
4 & 13.755645 & 26.74911 & 8.05732 & 263.61189 & 233.347565 & 54393.00 & $(1) 0.003$ \\
5 & 13.807123 & 27.08457 & 8.75527 & 256.77486 & 214.325228 & 54395.00 & $(1) 0.003$ \\
6 & 13.807085 & 27.12217 & 8.80445 & 256.35323 & 213.007088 & 54397.00 & $(1) 0.003$ \\
7 & 13.808004 & 26.97285 & 8.53223 & 258.85308 & 220.023952 & 54403.00 & $(1) 0.002$ \\
8 & 13.812803 & 27.00257 & 8.59691 & 258.23552 & 218.318487 & 54405.00 & $(5) 0.005$ \\
9 & 13.783138 & 27.238 & 8.81498 & 255.98918 & 212.613805 & 54429.00 & $(1) 0.0007$ \\
10 & 13.825026 & 26.92995 & 8.46453 & 259.48998 & 221.711473 & 54430.00 &
\end{tabular}

local optimization techniques viz. LFOPC, Dynamic - Q and ETOPC. The drawback of local optimization techniques is that it does not guarantee global optimum and also result changes with the change in starting point and thus they are time consuming with respect to global optimization techniques.

$\mathrm{ABC}$ algorithm used for the analysis was coded in MAT$\mathrm{LAB}$ and all experiments were done on $1.4 \mathrm{GHz}$ Intel Core 2 Duo Laptop machine. The performance of all the algorithms is compared for both the examples. To obtain the most suitable parameters a large number of experiments were conducted. For ABC the value of limit is set to $N \times S$ where $N$ is the number of employed or onlooker bees and $S$ is the dimension of design variable. One hundred trial runs were performed for each vari- ant of $\mathrm{ABC}$ algorithm for each example. The performances of the different variants were compared based on different criteria. The first criterion for the comparison is the best solution obtained in one run. The algorithms are compared for the best value, mean value and the standard deviation for one hundred runs for the best solutions. In this comparison best value gives the global optima, and mean value serves the purpose for the average performance to search optimum result. Standard deviation gives the deviation of best result from the mean result for all the runs. The second criterion for the comparison is the success rate, which indicates the percentage success the technique has achieved in finding the global solution. Results of all the benchmark problems are shown in the Table 1. 
It can be seen from the Table 1 that modified $\mathrm{ABC}$ is better than classical $\mathrm{ABC}$ in finding the best solution for both constraint and unconstraint benchmark problems. For Griewank and pressure vessel problem classical $\mathrm{ABC}$ has shown better result than modified $\mathrm{ABC}$ for the mean of the beat solutions. These results do not indicate that classical $\mathrm{ABC}$ is inferior to modified $\mathrm{ABC}$, but main intension of comparison is that modified $\mathrm{ABC}$ can find better solution with less population size and number of generations which indicates better convergence rate of the modified $\mathrm{ABC}$. If population size and number of generation is increased than both the variants converge to the same solution.

All the variants were experimented by taking different population size and different number of generations to study its effect on best solution, average solution, success rate and processing time for the considered two examples of welded structures.

Tables 2 and 3 show the best solutions for both the examples It is observed from the result that ABC 2 has shown better results than other two variants for best, mean solutions and standard deviations. All the variants have given improvement in the result with the increase in population size and number of generations. Moreover $\mathrm{ABC}_{2} 2$ require less function evaluation to reach optimum solution than $\mathrm{ABC}$ 1. For example 2 also similar kinds of results are observed. Moreover ABC 2 has given the optimum solution using less than 10000 function evaluations, which is better than the results of PSO implemented by Jarmai (2006), which requires between 26184 and 100000 function evaluations considering a population size of 500 . Results show the better performance of ABC over PSO in terms of solution as well as in terms of function evaluations

Tables 4 and 5 show the success rate for both the examples. Here success is calculated if the results are within the tolerance of $1 \%$ of its global optima. It is observed that here also $A B C \_2$ has better success rate with less population size and number of generations. With the increase in population size and number of generations success rate increases for all the variants. There is tremendous difference in the success rates of $\mathrm{ABC} 2$ and $\mathrm{ABC}$ 1. It is clear from the above discussion than $\mathrm{ABC} 2$ is a promising variant of $\mathrm{ABC}$ which serves all the requirement of a design engineer such as success rate and convergence of the solutions.

Example 1 has already been solved by many researchers and results from all the researchers are given in Table 6. It can be seen from the Table 5 that the best feasible solution found by $\mathrm{ABC}$ is better with respect to value of objective function than the best solutions found by other researchers using different optimization techniques. Results obtained by $\mathrm{ABC}$ are feasible because all the constraints are having negative values and thus satisfied.

More top ten solutions for both the examples are given in Tables 7 and 8 obtained by using ABC to help other researchers to check other optimization algorithms.

\section{Conclusions}

In the present work, cost optimization of welded structures has been presented. For orthogonally stiffened cylindrical shells cost function consist of material cost, manufacturing cost and painting cost. Shell buckling, stringer buckling, panel ring buckling and manufacturing limitations are considered as constraints. Classical $\mathrm{ABC}$ is modifies and it is applied on many constrained and unconstrained optimization benchmark problems and also to the optimization of welded structures. It is shown that $\mathrm{ABC}$ is capable of solving complicated cost optimization problems for welded structures. In terms of quality of solution, the results have shown that modified $\mathrm{ABC}$ has produced better results than classical $\mathrm{ABC}$. It is also shown that $\mathrm{ABC}$ has given better results than other optimization techniques.

\section{References}

1. AISC. 1970. Specification for the Design, Fabrication and Erection of Structural Steel for Buildings, Manual of Steel Construction, 7th edn. Chicago, Illinois: American Institute of Steel Construction.

2. AISC. 1978. Manual of Steel Construction, 8th edn. Chicago, Illinois: American Institute of Steel Construction.

3. AISC. 1986. Manual of Steel Construction - Load and Resistance Factor Design, 8th edn. Chicago, Illinois: American Institute of Steel Construction.

4. Anderson KE, Chong KP. 1986. Least cost computer-aided design of steel girders. Engineering Journal. AISC, Fourth Quarter, 151-156.

5. Basturk B, Karaboga D. 2006. An Artificial Bee Colony (ABC) Algorithm for Numeric Function Optimization, IEEE Swarm Intelligence Symposium, May 12-14, Indianapolis, Indiana, USA.

6. Belegundu AD. 1982. A study of mathematical programming methods for structural optimization, Doctoral dissertation, Department of Civil and Environmental Engineering, University of Iowa, Iowa City, Iowa.

7. Bhatti MA. 1996. Optimum cost design of partially composite steel beams using LRFD. Engineering Journal. AISC, First Quarter. p. 18-29.

8. Coello CAC, Montes EM. 2002. Constraint-handling in genetic algorithms through the use of dominance-based tournament selection. Advanced Engineering Informatics, 16, 193-203.

9. Coello CAC. 2000. Use of a self-adaptive penalty approach for engineering optimization problems. Computers in Industry, 41, 113-127.

10. Deb K. 1991. Optimal design of a welded beam via genetic algorithms. AIAA Journal, 29(11), 2013-2015.

11. Det Norske Veritas (DNV). 1995. Buckling strength analysis, Classification Notes No. 30.1. Ed. Det Norske Veritas, Hovik, Norway.

12. Dong Y, Tang J, Xu B, Wang D. 2005. An application of swarm optimization to nonlinear programming. Computer and Mathematics with Applications, 49, 1655-1668.

13. Douty R. 1980. Design of steel connections by math programming. Journal of the Structural Division, ASCE, 106(ST5), $1135-1154$.

14. Farkas J, Jarmai K. 2008. Minimum cost design of a square box column composed from orthogonally stiffened welded steel plates, International conference proceedings on design fabrication and economy of welded structures, Hungary. p. 70-71.

15. Farkas J. 1991. Fabrication aspects in the optimum design of welded structures. Structural Optimization, 3(1), 51-58. 
16. Farkas J, Jarmai K. 1994. Minimum cost design of laterally loaded welded rectangular cellular plates. Structural Optimization, 8(4), 262-267.

17. Farkas J, Jarmai K, Snyman J. 2009. Global minimum cost design of a welded square stiffened plate supported at four corners, Structural and Multidisciplinary Optimization, 40, 477489.

18. Farkas J. 2002. Thickness design of axially compressed unstiffened cylindrical shells with circumferential welds. Welding in the World, 46, 26-29.

19. Hojjat A, Kamal C. 2006. Cost Optimization of Structures, Fuzzy Logic, Genetic Algorithms and Parallel Computing. John Wiley: UK.

20. Jarmai K. 2007. Single- and multiobjective optimization of a welded stringer-stiffened cylindrical shell. Periodica Polytechnica, 51(2), 11-18.

21. Jarmai K, Snyman JA, Farkas J. 2006. Minimum cost design of a welded orthogonally stiffened cylindrical shell. Computers and Structures, 84, 787-797.

22. Karaboga D. 2005. An idea based on honey bee swarm for numerical optimization, Technical Report-TR06, Erciyes University, Engineering Faculty, Computer Engineering Department.

23. Karaboga D, Basturk B. 2007. Artificial bee colony (abc) optimization algorithm for solving constrained optimization problems, in IFSA 2007, LNAI 4529, Melin Pet al., Editors. Springer-Verlag: Berlin, Heidelberg. p. 789-798.

24. Karaboga D, Basturk B. 2008. On the performance of artificial bee colony $(\mathrm{ABC})$ algorithm. Applied Soft Computing, 8, 687697.
25. Lorenz RF. 1988. Understanding composite beam design methods using LRFD. Engineering Journal. AISC, First Quarter. p. 35-38.

26. Luis MCS, Farkas J, Jarmai K. 2008. Optimization of an orthogonally stiffened plate considering fatigue constraints, International conference proceedings on design fabrication and economy of welded structures, Hungary. p. 27-34.

27. Marcin C, Farkas J, Andrej G, Jarmai K, Katarzyna R. 2008. Optimization of steel beams and columns for variable rib configuration, International conference proceedings on design fabrication and economy of welded structures, Hungary. p. 113118.

28. Montes EM, Coello CAC. 2005. Useful Infeasible Solutions in Engineering Optimization with Evolutionary Algorithms. LNAI, 3789, 652-662.

29. Qie H, Ling W. 2007. An effective co-evolutionary particle swarm optimization for constrained engineering design problems. Engineering Applications of Artificial Intelligence, 20, 89-99.

30. Ragsdell KM, Phillips DT. 1976. Optimal design of a class of welded structures using geometric programming. ASME Journal of Engineering for Industries, 98(3), 1021-1025.

31. Ray T, Liew K. 2003. Society and civilization: an optimization algorithm based on the simulation of social behavior. IEEE Transactions on Evolutionary Computation, 7, 386-396.

32. Sandgren E. 1988. Nonlinear integer and discrete programming in mechanical design, Proceedings of the ASME Design Technology Conference, Kissimine, FL. p. 95-105.

Cite this article as: Savsani V: Implementation of modified artificial bee colony (ABC) optimization technique for minimum cost design of welded structures. Int. J. Simul. Multisci. Des. Optim., 2014, 5, A11. 